DOI: 10.20472/IAC.2018.036.005

CHUENJIT CHANGCHENKIT

Kasetsart University , Department of Marketing , Faculty of Business Administration, Thailand

\title{
THE SOCIAL MEDIA EXPOSURE AND ONLINE CLOTHES BUYING BEHAVIOR IN THAILAND
}

\begin{abstract}
:
The purpose of this research was to study social media exposure and online clothes buying behavior. Quantitative research consisting of 400 samples was employed to those who had at least 1 year experience on online buying clothes via social media exposure in Bangkok Metropolitan. Data was collected through online questionnaires with convenience sampling method. The results revealed that most of the respondents were female, aged between 26 - 35 years old, held bachelor degree,

had marital status of single, were private firm's employees and earned monthly income between 10,001 - 15,000 Thai baht. They made their own purchase via online shops via Facebook for latest collection. Their purchase decision making was influenced by online products reviews. The important step of buying process was information searching about products on social network. The hypothesis testing results showed that different demographic factors led to different decision making procedures on clothes online buying through social media. The difference in demographic factors also affect social media exposure behavior at a statistical significance level of 0.05 .
\end{abstract}

\section{Keywords:}

Social Media, Media Exposure, Online Buying Behavior, Clothes, Thailand

JEL Classification: M31 